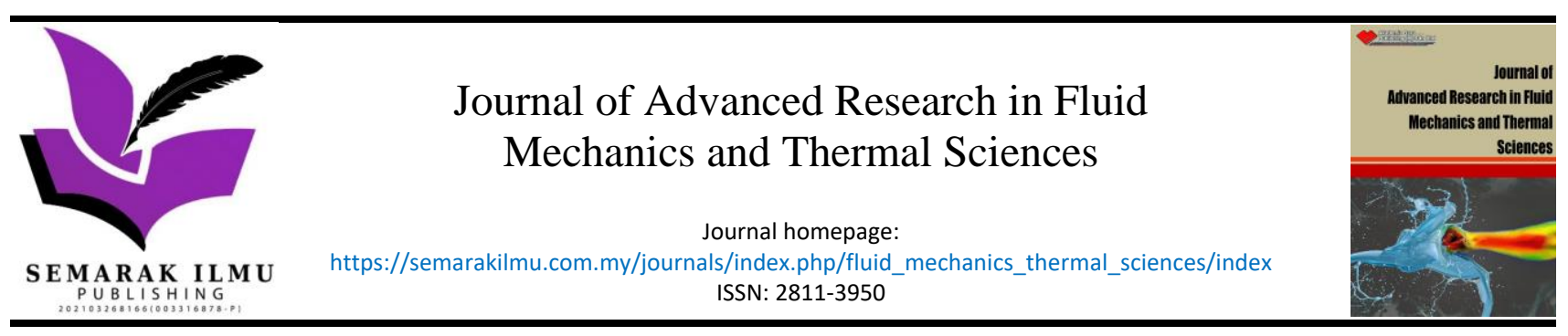

\title{
Aligned Magnetohydrodynamics (MHD) Flow of Hybrid Nanofluid Over a Vertical Plate Through Porous Medium
}

\author{
Asmahani Nayan ${ }^{1}$, Nur Izzatie Farhana Ahmad Fauzan ${ }^{2}$, Mohd Rijal Ilias ${ }^{3,}{ }^{*}$, Shahida Farhan Zakaria ${ }^{1}$, \\ Noor Hafizah Zainal Aznam ${ }^{1}$ \\ Faculty of Computer and Mathematical Sciences, Universiti Teknologi MARA Cawangan Kedah, 08400 Merbok, Kedah, Malaysia \\ Pusat Tuisyen Ilham IImu, No. 33, Tingkat 1, Jalan BDSJ 5, Blok Dagangan Jengka Sejahtera, 26400 Bandar Jengka, Pahang, Malaysia \\ Faculty of Computer and Mathematical Sciences, Universiti Teknologi MARA Shah Alam, 40450 Shah Alam, Selangor, Malaysia
}

ARTICLE INFO

\section{Article history:}

Received 7 October 2021

Received in revised form 23 December 2021

Accepted 29 December 2021

Available online 30 January 2022
Keywords:

Aligned MHD; Constant Wall Boundary; Boundary Condition; Vertical Plate; Porous Medium

\section{ABSTRACT}

The future research on hybrid nanofluids need to be done as there are many applications of hybrid nanofluids. Some of them are electro-mechanical, renewable energy and manufacturing process application and also the application in automotive cooling. Therefore, this numerical study is conducted to investigate the aligned magnetohydrodynamics (MHD) flow of hybrid nanofluid over a vertical plate through a porous medium. The base fluid (water), silver and copper oxide flowed over a vertical plate in the presence of MHD and porous medium with boundary conditions of constant wall temperature by taking a few types of parameters into consideration. By using similarity transformation, the governing nonlinear partial differential equations are transformed into nonlinear ordinary differential equations. Keller Box method is applied to solve numerically the nonlinear ordinary differential equations and the system is solved by using Fortran programming. The results of the study are illustrated graphically to show the behavior of velocity and temperature also skin friction and Nusselt number of hybrids nanofluid affected by the parameters. It is found that the velocity profiles increase, and temperature profiles decrease when the angle of aligned magnetic field, the interaction of magnetic parameter and local Grashof number increase while the velocity profiles decrease, and temperature profiles increase when the porous parameter and volume fraction of nanoparticles parameter increase. Besides, the skin friction of $\mathrm{Ag}$-CuO-water is less than $\mathrm{CuO}$-water and Nusselt number of $\mathrm{Ag}$-CuO-water is higher than CuO-water.

\section{Introduction}

Last two decades, there was a revolution on all scientific research because of the use of nanotechnology or also known as new technology [1]. Nanotechnology is a manipulation of the individual molecules and atoms which is a part of a technology that deals with dimensions and tolerances of below 100 nanometres. Nanotechnology creates many new devices and materials for a large range of applications. For example, the application in nanoelectronics, nanomedicine,

\footnotetext{
* Corresponding author.

E-mail address: mrijal@uitm.edu.my
}

https://doi.org/10.37934/arfmts.92.1.5164 
consumer product, and biomaterials energy production. Furthermore, nanotechnology is the process of utilization of metals and oxides. Nanofluid is a new heat transfer fluid class introduced by Choi and Eastman [2] for the first time. Based on Choi and Eastman [2] and Eastman et al., [3], nanofluid is proposed to show the components of nanoparticles dispersed in a base fluid. Ganga et al., [4] investigated the hydromagnetic flow of an incompressible viscous nanofluid in the presence of thermal radiation past a vertical plate. They believe that nanofluids are additives which additives are a method used to increase the efficiency of heat transfer of base fluids. Hussanan et al., [5] studied the unsteady free convection flow of five different types of oxide nanoparticles suspended micropolar nanofluid over a vertical plate. It founds that velocity of $\mathrm{Al}_{2} \mathrm{O}_{3}$ based nanofluid is higher than other oxide nanoparticles based nanofluid for every values nanoparticle volume fraction. Also, Hussanan et al., [6] explores the impact of viscous dissipation on unsteady two-dimensional boundary layer flow of viscoplastic Casson ferrofluid over semi-infinite vertical plate with leading edge accretion/ablation. There are several studies in nanofluid in different situation $[7,8]$.

Besides that, the heat transfer performance can be more increased by using hybrid nanofluid. Hybrid nanofluid is a relation between two or more types of nanoparticles that hang in a base fluid and a combination of favorable physical and chemical properties that will make it more stable and boost thermophysical properties [9]. Khashi'ie et al., [10] analyze the mixed convection of hybrid Cu$\mathrm{Al}_{2} \mathrm{O}_{3}$ /water along a static plate in a non-Darcy porous medium with thermal dispersion. It founds that the hybrid nanofluid temperature decreases with an increment in thermal dispersion and mixed convection parameters. Waini et al., [11] studied about steady mixed convection flow along a vertical surface embedded in a porous medium with hybrid nanoparticles. It is noticed that the added hybrid nanoparticles delay the separation of the boundary layer. In addition, the velocity of the hybrid nanofluid is increased for the upper branch solutions, but the observation is reversed for the lower branch solutions as Cu nanoparticle increases. In the others way, there are various studies in hybrid nanofluid [12-16].

MHD consists of liquid and magnetic properties which are the magnetic field influences the adjourned particles and rearranges their concentration in the fluid regime which strongly influences the heat transfer analysis [17]. The study done by Reddy et al., [18] investigates the numerical solution of unsteady aligned MHD flow of magnetic nanofluids over an inclined plate with leading edge accretion. They found that the leading-edge accretion can significantly alter the fluid motion and the heat transfer attributes. The numerical study of natural boundary layer flow of MHD ferrofluids over a flat plate with aligned magnetic field by Ilias et al., [19] and found that the heat transfer rate at the plate surface is increase with increasing angle of magnetic field, magnetic field parameter, ferroparticle volume fraction and local Grashof number. There are several studies in MHD in different situation [20-25].

Porous medium is defined as a solid matrix containing pores that are typically filled with fluid [26]. Porous medium is also known as porous material. The porous medium is considered as rigid and open cell saturated because the pores are connected and filled with fluid completely so that the fluid can flow through the pores. Goud et al., [27] studied unsteady MHD free convection flow with mass and heat transfer past an inclined plate. They discussed the effects of the porous medium on related material parameters, magnetic field, and permeability. It shows the flow reversal in porous water, with an active magnetic field, and for angle of inclination and heat source a retarding velocity is observed. Das et al., [28] analyzed the presence of a transverse magnetic field a MHD flow of AlO/water nanofluid and Cu-AlO / water hybrid nanofluid through a porous channel. Mansour et al., [29] also study the natural convection flow and heat transfer of the entropy generation and magnetohydrodynamics in a square porous cavity differentially heated and cooled by the heat source 
and sink filled with the $\mathrm{Cu}-\mathrm{Al}_{2} \mathrm{O}_{3}$-Water hybrid nanofluid. Other studies on porous medium were discuss in [30-33].

There are studies about constant wall temperature boundary condition. Anwar et al., [34] evaluate the physical effects of application of simultaneous ramped wall velocity and ramped wall temperature condition on unsteady, MHD convection flow of some nanofluids over an infinite vertical plate. The Darcy's law is applied to encounter the porosity of the medium and found that the temperature, velocity, shear stress and rate of heat transfer, respective profile behaves in a similar manner for both ramped wall and isothermal wall boundary conditions. In the study by Pasha et al., [35], the dissipation of heat in tiny engineering systems can be achieved with fluid flow through micro pipes. There are deep-rooted analytical relations for convective heat transfer available for fluid flow through macro size pipes. But differences exist between the convective heat transfer for fluid flow through macro and micro pipes with either constant heat flux wall boundary conditions or constant wall temperature boundary conditions with constant and variable property flows. They found that with variable and constant property flows of varying Reynolds numbers, the conventional pipe exhibited no significant difference. The Nusselt number with variable property flows is lower than with constant property flows, as shown by the flow through a 3D micropipe. Besides, various researchers did the investigation of constants wall temperature under different situations [36-38].

This paper focuses on the effects an aligned magnetic field of hybrid nanofluid over a vertical plate through porous medium with constant wall boundary condition. The study of this research is to understand of how the aligned angle of interaction parameter, the interaction of magnetic parameter, volume fraction of magnetic nanoparticles parameter, local Grashof number, Biot numbers, and porous medium parameter affect velocity and temperature, as well as skin friction and Nusselt number hybrid nanofluid. The governing equations is simplified by using similarity transformations and finally the obtained model is illustrated numerically by using Keller Box method.

\section{Mathematical Formulation}

This study considers a continuous, incompressible two-dimensional free convection flow of hybrid nanofluids over a smooth vertical plate in the presence of porous medium and aligned magnetic field with constant wall temperature. The mixtures of magnetic nanofluid used in this study was copper oxide $(\mathrm{CuO})$ and water and hybrid nanofluid used in this study was Silver ( $\mathrm{Ag})$, copper oxide ( $\mathrm{CuO}$ ) and water. The aligned magnetic field with an acute angle, $\alpha$ is applied to the flow. It is recognized as a function of the distance from the origin expressed as $B(x)=\frac{B_{0}}{\sqrt{x}}$ with $B_{0} \neq 0$.

Figure 1 shows the physical model used in the simulation. It is a figure of the boundary layer of MHD hybrid nanofluid flow through porous medium over a vertical plate. Here $B_{0}$ is the strength of the magnetic field and $x$ is the coordinate along the plate. The base fluids (water) and nanoparticles (silver ( $\mathrm{Ag})$ and copper oxide ( $\mathrm{CuO}$ ) nanoparticles) are in thermal equilibrium and the shape of nanoparticles is spherical. The surface of the plate is maintained at a constant temperature $T_{w}$ higher than the temperature $T_{\infty}$ of the ambient nanofluid. The equations of boundary layer flow given as: 


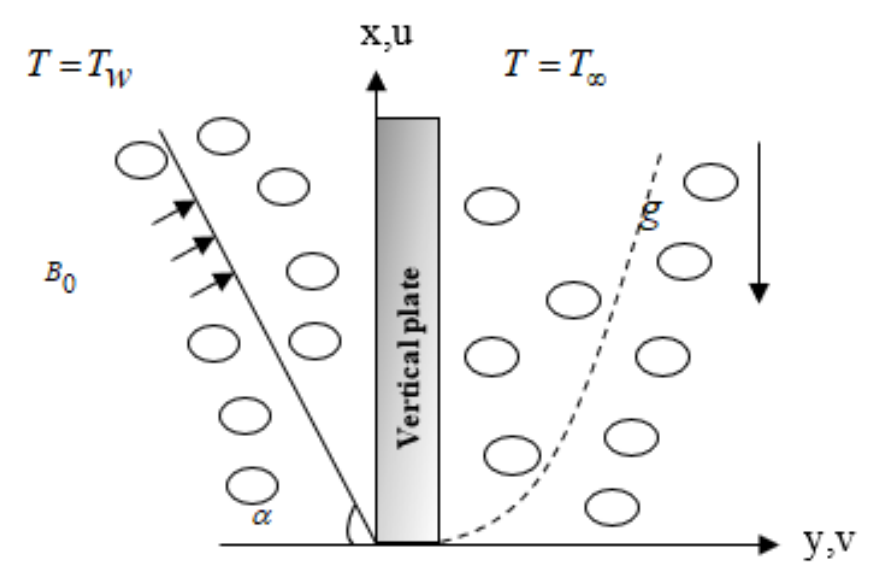

Fig. 1. Physical Model of Constant Wall Temperature

$\frac{\partial u}{\partial x}+\frac{\partial v}{\partial y}=0$

$u \frac{\partial u}{\partial x}+v \frac{\partial u}{\partial y}=\frac{\mu_{h n f}}{\rho_{h n f}} \frac{\partial^{2} u}{\partial y^{2}}+\frac{(\rho \beta)_{h n f}}{\rho_{h n f}} g\left(T-T_{\infty}\right)-\left(\frac{\sigma B^{2}(x)}{\rho_{h n f}}+\frac{\mu_{h n f}}{\rho_{h n f} K_{p}}\right) \sin ^{2} \alpha\left(u-U_{\infty}\right)$

$u \frac{\partial T}{\partial x}+v \frac{\partial T}{\partial y}=\alpha_{h n f} \frac{\partial^{2} T}{\partial y^{2}}$

The boundary conditions for the velocity and temperature of this problem are given by

$$
\begin{aligned}
& u=0, \quad v=0, \quad T=T_{w} \quad \text { on } \quad y=0 \\
& u \rightarrow U_{\infty}, \quad T \rightarrow T_{\infty} \quad \text { as } \quad y \rightarrow \infty
\end{aligned}
$$

where $u$ is the fluid velocity and $v$ is the normal velocity components along the $\mathrm{x}$-and $\mathrm{y}$-axes. $\alpha$ is the angle of aligned magnetic field, $T_{w}$ is the constant wall temperature, $T$ is the temperature of the fluid, $T_{\infty}$ is the free stream temperature, $\sigma$ is the electrical conductivity, $g$ is the gravity acceleration and $U_{\infty}$ is the free stream velocity. The thermophysical relations of nanofluids as follow [39].

$$
\begin{aligned}
& \rho_{h n f}=\left(\left(1-\phi_{2}\right)\left(\left(1-\phi_{1}\right) \rho_{f}+\phi_{1} \rho_{s 1}\right)\right)+\phi_{2} \rho_{s 2}, \mu_{h n f}=\frac{\mu_{f}}{\left(1-\phi_{1}\right)^{2.5}\left(1-\phi_{2}\right)^{2.5},} \\
& \left(\rho C_{p}\right)_{h n f}=\left(1-\phi_{2}\right)\left(\left(1-\phi_{1}\right)\left(\rho C_{p}\right)_{f}+\phi_{1}\left(\rho C_{p}\right)_{s 1}\right)+\phi_{2}\left(\rho C_{p}\right)_{s 2}, \alpha_{h n f}=\frac{k_{h n f}}{\left(\rho C_{p}\right)_{h n f}}, \\
& \frac{k_{h n f}}{k_{f}}=\frac{k_{s 2}+2 k_{b f}-2 \phi_{2}\left(k_{b f}-k_{s 2}\right)}{k_{s 2}+2 k_{b f}+\phi_{2}\left(k_{b f}-k_{s 2}\right)} \times \frac{k_{s 1}+2 k_{f}-2 \phi_{1}\left(k_{f}-k_{s 1}\right)}{k_{s 1}+2 k_{f}+\phi_{1}\left(k_{f}-k_{s 1}\right)}, \\
& (\rho \beta)_{h n f}=\left(\left(1-\phi_{2}\right)\left(\left(1-\phi_{1}\right)(\rho \beta)_{f}+\phi_{1}(\rho \beta)_{s 1}\right)\right)+\phi_{2}(\rho \beta)_{s 2}, \\
& \beta_{h n f}=\left(\left(1-\phi_{2}\right)\left(\left(1-\phi_{1}\right) \beta_{f}+\phi_{1}(\rho \beta)_{s 1}\right)\right)+\phi_{2} \beta_{s 2}
\end{aligned}
$$


where $\rho_{h n f}$ is the effective density, $(\rho \beta)_{h n f}$ is the thermal expansion coefficient, $\mu_{h n f}$ is the effective dynamic viscosity and $\alpha_{h n f}$ is the thermal diffusivity of the fluid, $\left(\rho C_{p}\right)_{h n f}$ is the heat capacity of the fluid, $k_{h n f}$ is the thermal conductivity of the fluid, $M$ is the magnetic parameter, Pr is the Prandtl number and $G r_{x}$ is the local Grashof number, and $K_{p}$ is the porous medium. The thermophysical properties of base fluid, copper oxide and silver nanoparticles are given in Table 1 [40].

Table 1

Thermophysical properties of base fluids and nanoparticles [40]

\begin{tabular}{llll}
\hline Properties & Base Fluid (Water) & CuO (Copper Oxide) & $\mathrm{Ag}$ (Silver) \\
\hline$\rho\left(\mathrm{kg} / \mathrm{m}^{3}\right)$ & 997.1 & 6320 & 10500 \\
$C_{p}(\mathrm{~J} / \mathrm{kgK})$ & 4179 & 531.8 & 235 \\
$k(\mathrm{~W} / \mathrm{mK})$ & 0.613 & 76.5 & 429 \\
$\beta \times 10^{-5}$ & 21 & 1.80 & 1.89 \\
$\operatorname{Pr}$ & 6.20 & & \\
\hline
\end{tabular}

The continuity equation in (1) is satisfied by introducing the stream function $\psi=(x, y)$ of the form which is related to $u$ and $v$ as below

$u=\frac{\partial \psi}{\partial y}, \quad \mathrm{v}=-\frac{\partial \psi}{\partial x}$

The similarity variable $\eta$ and the dependent variable $f$ of stream function as below

$\eta=\frac{y}{x}\left(\operatorname{Re}_{x}\right)^{\frac{1}{2}}, \quad \psi=v_{f} \sqrt{\operatorname{Re}_{x}} f(\eta), \quad \theta=\frac{T-T_{\infty}}{T_{w}-T_{\infty}}$

where $\operatorname{Re}_{x}=\frac{U_{\infty} x}{v_{f}}$ is the Reynolds number. By using similarity transformation, (5), (6) and (7) were substitute into (2) and (3) in order to reduce to the following nonlinear system of ordinary differential equations as below:

$$
\begin{aligned}
& f^{\prime \prime \prime}(\eta)+\left(1+\phi_{1}\right)^{2.5}\left(1-\phi_{2}\right)^{2.5}\left[\left(1-\phi_{2}\right)\left(\left(1-\phi_{1}\right)+\phi_{1} \frac{\rho_{s 1}}{\rho_{f}}\right)+\phi_{2} \frac{\rho_{s 2}}{\rho_{f}}\right] \frac{1}{2} f(\eta) f^{\prime \prime}(\eta)+ \\
& \left(1+\phi_{1}\right)^{2.5}\left(1-\phi_{2}\right)^{2.5}\left[\left(1-\phi_{2}\right)\left(\left(1-\phi_{1}\right)+\phi_{1} \frac{(\rho \beta)_{s 1}}{(\rho \beta)_{f}}\right)+\phi_{2} \frac{(\rho \beta)_{s 2}}{(\rho \beta)_{f}}\right] G r_{x} \theta+ \\
& \left(\left(1+\phi_{1}\right)^{2.5}\left(1-\phi_{2}\right)^{2.5} M+\frac{1}{K_{p}}\right) \sin ^{2} \alpha\left(1-f^{\prime}(\eta)\right)=0 \\
& \frac{k_{\text {hnf }}}{k_{f}} \theta^{\prime \prime}(\eta)+\frac{\operatorname{Pr}}{2}\left(\left(1-\phi_{2}\right)\left(\left(1-\phi_{1}\right)+\phi_{1} \frac{\left(\rho C_{p}\right)_{s 1}}{\left(\rho C_{p}\right)_{f}}\right)+\phi_{2} \frac{\left(\rho C_{p}\right)_{s 2}}{\left(\rho C_{p}\right)_{f}}\right) f(\eta) \theta^{\prime}(\eta)=0
\end{aligned}
$$


By subjecting to (4), the boundary conditions obtained were as follow:

$$
\begin{aligned}
& f(0)=0, \quad f^{\prime}(0)=0, \quad \theta(0)=1, \quad \text { at } \quad \eta=0 \\
& f^{\prime}(\eta) \rightarrow 1 \quad \theta(\eta) \rightarrow 0 \quad \text { as } \quad \eta \rightarrow \infty
\end{aligned}
$$

where $G r_{x}=\frac{g \beta_{f}\left(T_{w}-T_{\infty}\right) x}{U_{\infty}{ }^{2}}, M=\frac{\sigma B_{0}{ }^{2}}{\rho_{f} U_{\infty}}, K_{p}=\frac{v_{f} x}{K U_{\infty}}=\frac{\mu_{f} x}{K \rho_{f} U_{\infty}}, \operatorname{Pr}=\frac{\left(\mu C_{p}\right)_{f}}{k_{f}}$, and $v_{f}=\frac{\mu_{f}}{\rho_{f}}$ is the kinematic viscosity of base fluid. The quantities of engineering interest are the skin-friction coefficient, $c_{f}$ at the surface of the plate and local Nusselt number, $N u_{x}$ which are defined as:

$$
C_{f}=\frac{\tau_{w}}{\rho_{f} U_{\infty}^{2}}, \quad N u_{x}=\frac{x q_{w}}{k_{f}\left(T_{w}-T_{\infty}\right)}
$$

where $\tau_{w}$ is the shear stress or wall skin friction and $q_{w}$ is the plate's heat flux which given by:

$$
\tau_{w}=\mu_{h n f}\left(\frac{\partial u}{\partial y}\right)_{y=0}, \quad q_{w}=-k_{h n f}\left(\frac{\partial T}{\partial y}\right)_{y=0}
$$

By substitute (7) and (12) into (11), the solutions obtained were as follow:

$$
\frac{c_{f}}{\operatorname{Re}_{x}^{-\frac{1}{2}}}=\frac{1}{\left(1-\phi_{1}\right)^{2.5}\left(1-\phi_{2}\right)^{2.5}} f^{\prime \prime}(0), \quad \frac{N u_{x}}{\left(\operatorname{Re}_{x}\right)^{\frac{1}{2}}}=\frac{-k_{n f}}{k_{f}} \theta^{\prime}(0)
$$

\section{Results and Discussion}

The result explained are on the velocity and temperature profile as well as skin friction and Nusselt number effected by the parameter used in this paper is presented using graphs and tables. Table 2 shows the comparison of the present analysis with the numerical results reported by previous researchers. The present results are in good agreement with results from past papers for the validation. 


\section{Table 2}

Comparison results of skin friction for different values of $\phi_{1}$ when $G r_{x}=0, \phi_{2}=0, M=0, K_{p}=0, \alpha=0$ and $\frac{k_{n f}}{k_{f}}=1$

\begin{tabular}{|c|c|c|c|c|c|c|}
\hline \multirow[t]{3}{*}{$\phi_{1}$} & \multicolumn{3}{|c|}{ Cu-Water } & \multicolumn{3}{|l|}{$\mathrm{Al}_{2} \mathrm{O}_{3}$-Water } \\
\hline & \multirow{2}{*}{$\begin{array}{l}\text { Skin } \\
\text { Friction } \\
{[41]}\end{array}$} & \multicolumn{2}{|l|}{ Present } & \multirow{2}{*}{$\begin{array}{l}\text { Skin Friction } \\
{[41]}\end{array}$} & \multicolumn{2}{|l|}{ Present } \\
\hline & & Skin Friction & $\begin{array}{l}\text { Nusselt } \\
\text { Number }\end{array}$ & & Skin Friction & $\begin{array}{l}\text { Nusselt } \\
\text { Number }\end{array}$ \\
\hline 0 & 0.3321 & 0.332059 & 0.620077 & 0.3321 & 0.332059 & 0.620077 \\
\hline 0.002 & 0.3355 & 0.335530 & 0.623559 & 0.3339 & 0.333882 & 0.622419 \\
\hline 0.004 & 0.3390 & 0.338997 & 0.627029 & 0.3357 & 0.335711 & 0.624760 \\
\hline 0.008 & 0.3459 & 0.345923 & 0.633934 & 0.3394 & 0.339386 & 0.629440 \\
\hline 0.01 & 0.3494 & 0.349382 & 0.637370 & 0.3412 & 0.341233 & 0.631780 \\
\hline 0.012 & 0.3528 & 0.352839 & 0.640796 & 0.3431 & 0.343085 & 0.634120 \\
\hline 0.014 & 0.3563 & 0.356294 & 0.644211 & 0.3449 & 0.344944 & 0.636459 \\
\hline 0.016 & 0.3597 & 0.359749 & 0.647617 & 0.3468 & 0.346809 & 0.638798 \\
\hline 0.018 & 0.3632 & 0.363202 & 0.651013 & 0.3487 & 0.348680 & 0.641136 \\
\hline 0.02 & 0.3667 & 0.366655 & 0.654400 & 0.3506 & 0.350558 & 0.643475 \\
\hline 0.1 & 0.5076 & 0.507637 & 0.784968 & 0.4316 & 0.431594 & 0.736999 \\
\hline 0.2 & 0.7066 & 0.706567 & 0.943462 & 0.5545 & 0.554512 & 0.855036 \\
\hline \multirow{3}{*}{$\phi_{1}$} & \multicolumn{3}{|c|}{$\mathrm{TiO}_{2}$-Water } & \multicolumn{3}{|l|}{ Water } \\
\hline & \multirow{2}{*}{$\begin{array}{l}\text { Skin } \\
\text { Friction } \\
{[41]}\end{array}$} & \multicolumn{2}{|l|}{ Present } & \multirow{2}{*}{$\begin{array}{l}\text { Skin Friction } \\
{[42]}\end{array}$} & \multicolumn{2}{|l|}{ Present } \\
\hline & & Skin Friction & $\begin{array}{l}\text { Nusselt } \\
\text { Number }\end{array}$ & & Skin Friction & $\begin{array}{l}\text { Nusselt } \\
\text { Number }\end{array}$ \\
\hline 0 & 0.3321 & 0.332059 & 0.620077 & 0.3321 & 0.332059 & 0.620077 \\
\hline 0.002 & 0.3340 & 0.333975 & 0.622127 & & 0.332558 & 0.617720 \\
\hline 0.004 & 0.3359 & 0.335897 & 0.624175 & & 0.333058 & 0.615368 \\
\hline 0.008 & 0.3398 & 0.339758 & 0.628264 & & 0.334065 & 0.610681 \\
\hline 0.01 & 0.3417 & 0.341698 & 0.630306 & & 0.334571 & 0.608345 \\
\hline 0.012 & 0.3436 & 0.343643 & 0.632346 & & 0.335079 & 0.606014 \\
\hline 0.014 & 0.3456 & 0.345594 & 0.634384 & & 0.335589 & 0.603689 \\
\hline 0.016 & 0.3476 & 0.347552 & 0.636420 & & 0.336100 & 0.601369 \\
\hline 0.018 & 0.3495 & 0.349516 & 0.638454 & & 0.336613 & 0.599055 \\
\hline 0.02 & 0.3515 & 0.351486 & 0.640486 & & 0.337128 & 0.596745 \\
\hline 0.1 & 0.4362 & 0.436237 & 0.720441 & & 0.359372 & 0.508614 \\
\hline 0.2 & 0.5642 & 0.564182 & 0.817461 & & 0.393037 & 0.409705 \\
\hline
\end{tabular}

Figure 2 to Figure 6 illustrate how velocity and temperature profiles change with different values of $\alpha, M, \phi_{1}, \phi_{2}, G r_{x}$ and $K_{p}$. While the numerical value of skin friction coefficient and Nusselt number for nanoparticle shapes are shown in Table 3.

Figure 2(a) depicts the effects of $\alpha$ on velocity profiles for CuO-Water and Ag/CuO-Water. The figure observed that increasing in $\alpha$, increase the velocity profiles for both CuO-Water and $\mathrm{Ag} / \mathrm{CuO}$ Water. It is further observed that the rise in $\alpha$ causes the boundary momentum layer to be decreased. The velocity of $\mathrm{CuO}$-Water is higher compared to $\mathrm{Ag} / \mathrm{CuO}$-Water. Figure 2(b) depicts the effects of $\alpha$ on temperature profiles for $\mathrm{CuO}-$ Water and $\mathrm{Ag} / \mathrm{CuO}-W a t e r$. It is observed that the temperature profiles decrease when the $\alpha$ increase for both $\mathrm{CuO}-W$ ater and $\mathrm{Ag} / \mathrm{CuO}-W a t e r$. This is because the rise in $\alpha$ causes the thermal boundary layer to decrease. $\mathrm{Ag} / \mathrm{CuO}-\mathrm{Water}$ has higher temperature compared to CuO-Water. When $\alpha=\frac{\pi}{2}$, it behaves like transverse magnetic field, and the nanoparticles are attracted by the magnetic field due to changes in aligned angle positions while 
$\alpha=0$ represents no magnetic interaction. As shown in Table 3, the skin friction coefficient and Nusselt number for nanofluid and hybrid nanofluid is increase as $\alpha$ increases.

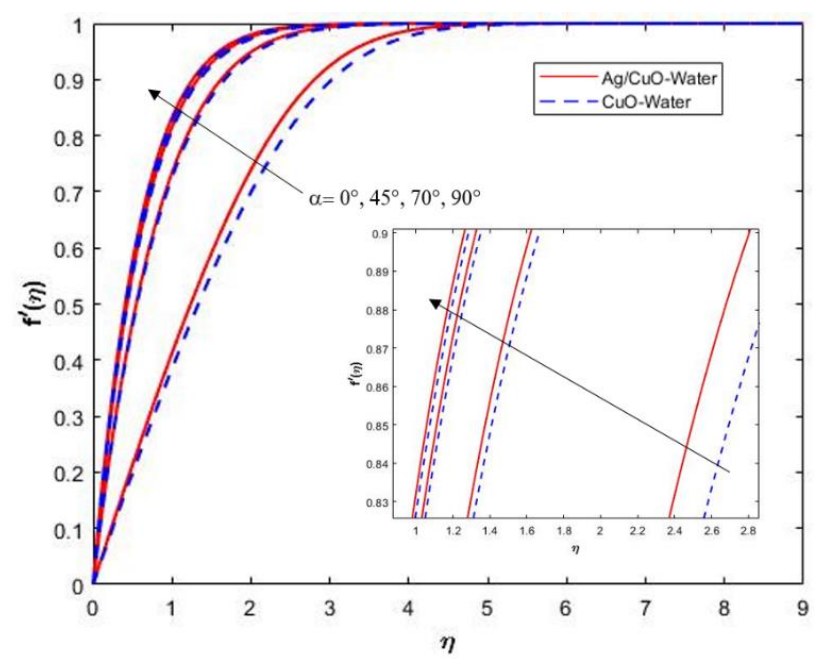

(a)

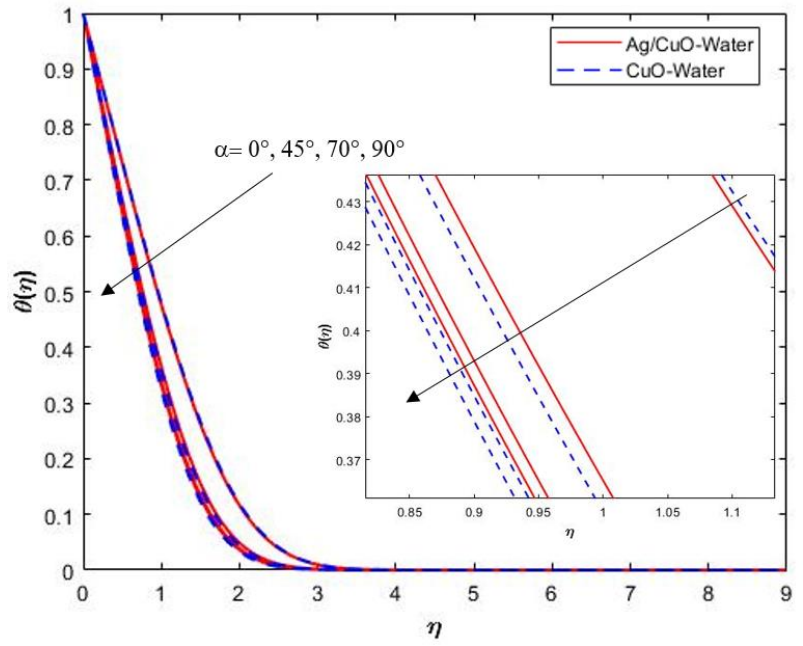

(b)

Fig. 2. Effects of $\alpha$ on (a) velocity profiles and (b) temperature profiles

Figure 3(a) represents the effects of $M$ on velocity profiles. It is shows that increasing in the value of $M$ increased the velocity profiles for both hybrid nanofluids and nanofluids. This is led to decrease the momentum boundary layer thickness because the nanoparticles usually arrange in sequence when the $M$ increase. The magnetic lines move as they move past the plate, based on the free stream velocity. $M$ pushes the fluid decelerated by viscous force which counteracts the viscous effects as well. The velocity profile of $\mathrm{Ag} / \mathrm{CuO}$-Water is greater than $\mathrm{CuO}$-Water. Figure $3(\mathrm{~b})$ represents the effects of $M$ on temperature profiles. Based on the figure, the temperature profiles decrease for both hybrid nanofluids and nanofluids when the value of $M$ increase. The behaviour of the temperature profiles is contrary with velocity profile, so it can be concluded that, the thermal boundary layer thickness is reduced as the magnitude $M$ increased. While for the skin friction and Nusselt number it shows in Table 3 when $M$ increase, all the value for both also increases for nanofluid and hybrid nanofluid.

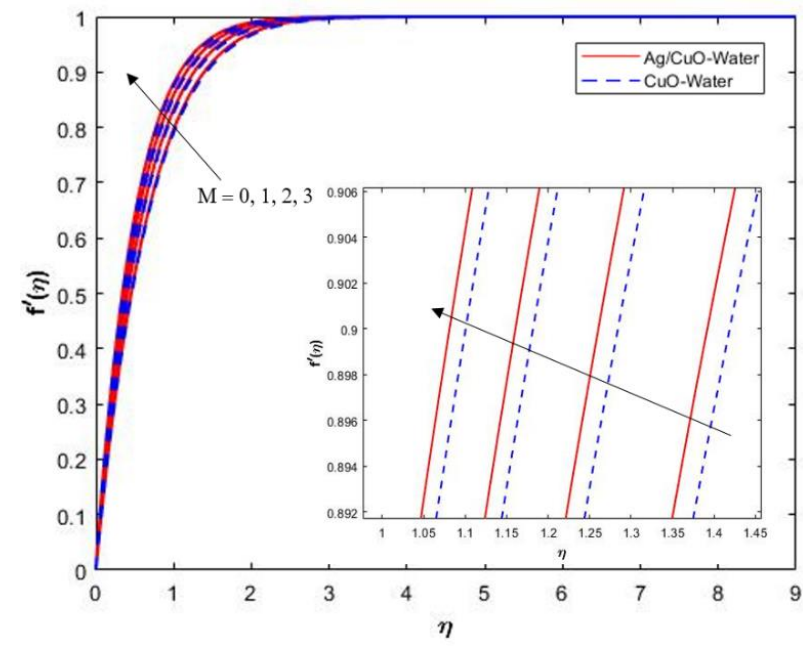

(a)

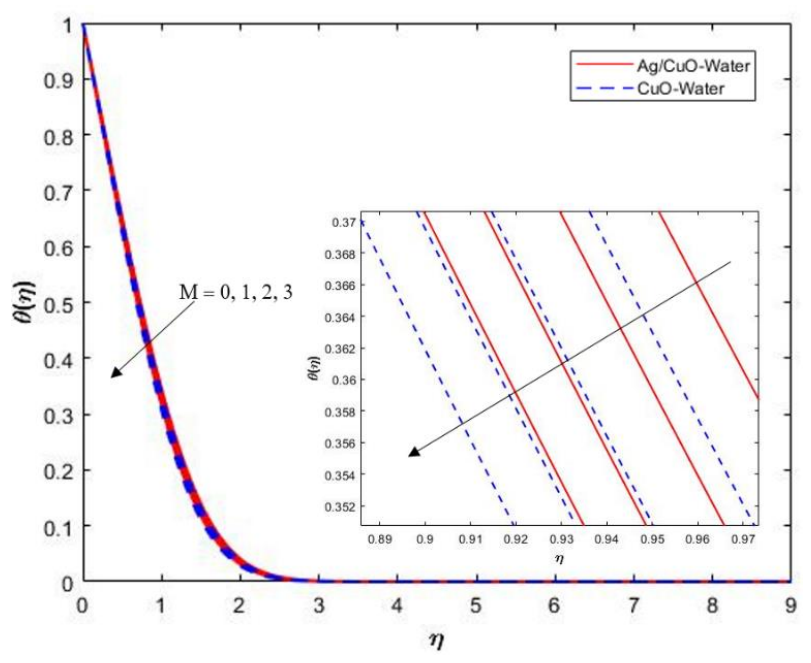

(b)

Fig. 3. Effects of $M$ on (a) velocity profiles and (b) temperature profiles 
Figure 4(a) displays the effects of $\phi_{1}$ and $\phi_{2}$ on velocity profile for hybrid nanofluid and nanofluid. The figure shows increasing in $\phi_{1}$ and $\phi_{2}$ for $\mathrm{Ag} / \mathrm{CuO}-$ Water and CuO-Water caused the velocity profiles decrease. It is due to the increase in $\phi_{1}$ and $\phi_{2}$ makes the fluid more viscous. Besides that, to be more specified, the Figure 4(a) shows the velocity CuO-Water is lower than $\mathrm{Ag} / \mathrm{CuO}$-Water, so it can be observed that CuO-Water more viscous than $\mathrm{Ag} / \mathrm{Cuo}-W a t e r$. The momentum boundary layer is increase for both nanofluid and hybrid nanofluid. Figure 4(b) displays the effects of $\phi_{1}$ and $\phi_{2}$ on temperature profiles for hybrid nanofluid and nanofluid. Based on the figure, the more $\phi_{1}$ and $\phi_{2}$, the greater the temperature profile. This is because the thermal boundary layer is increase steadily. Furthermore, it is consistent with the physical behavior where the thermal conductivity of the nanofluid increases with an increase in $\phi$ and hence the thickness of the boundary layer increases as well.

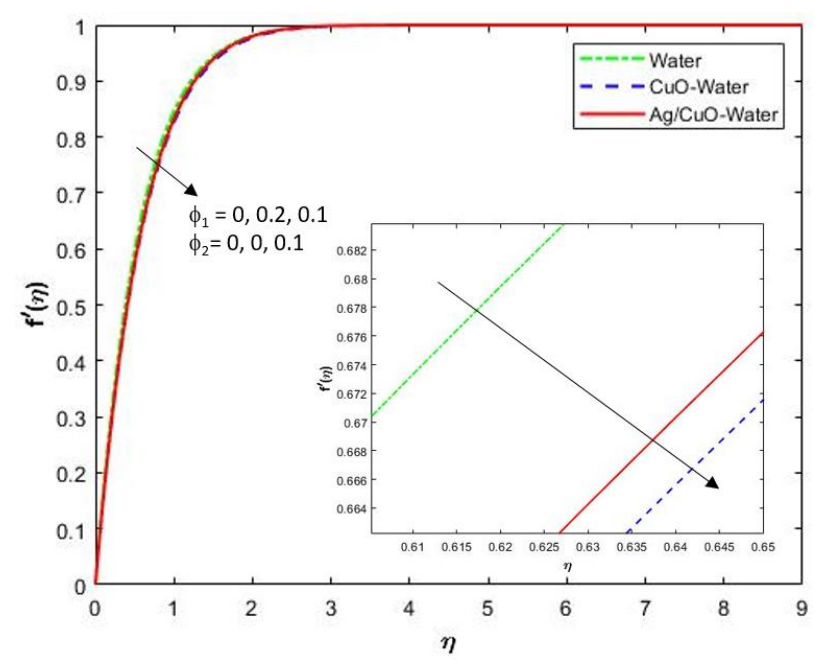

(a)

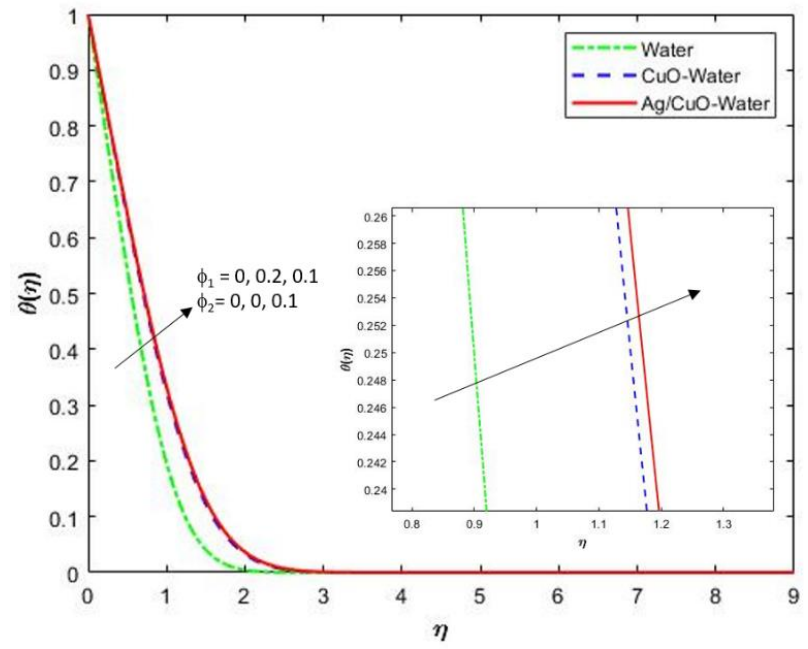

(b)

Fig. 4. Effects of $\phi_{1}$ and $\phi_{2}$ on (a) velocity profiles and (b) temperature profiles

Figure 5(a) shows the effects of $\mathrm{Gr}_{x}$ of $\mathrm{Ag} / \mathrm{CuO}-$ Water and CuO-Water on velocity profile. It is observed that the velocity profiles show an increase, a peak and then decrease gradually to free stream velocity value far away from the plate as satisfying the boundary conditions. However, it is noteworthy that the velocity profiles for $\mathrm{Ag} / \mathrm{CuO}-$ Water and $\mathrm{CuO}-$ Water increase when $G r_{x}$ increase. $G r_{x}$ also known as free convective parameter. The parameter for free convection can be positive, negative, or nil. For $G r_{x}=0$, it represents the no of free convection meanwhile for $G r_{x}>0$ represents the rise to the cooling problem which it indicates that $T_{w}>T_{\infty}$. Furthermore, when $G r_{x}<0$, it indicates $T_{w}<T_{\infty}$ which means the heat flow is from the fluid to the plate. Besides, when $G r_{x}$ increase, the buoyancy force also increases. This force increases the rate of heat transfer by convection. The greater convection is caused by temperature rise, which reduces the nanofluid density at a higher temperature. It is clear that when compared to a larger density fluid which is $\mathrm{Ag} / \mathrm{CuO}-$ Water, the fluid velocity of a smaller density, CuO-Water is greater. The momentum boundary layer decreases for both nanofluid and hybrid nanofluid. Figure 5(b) shows the effects of $G r_{x}$ on temperature profile for $\mathrm{Ag} / \mathrm{CuO}-W a t e r$ and CuO-Water. It is exhibit increasing in $G r_{x}$, decrease the temperature profile as well as thermal boundary layer thickness. It accepts that due to buoyancy force there is a rise in the fluid velocity, which then resulted in a decrease in the fluid temperature. 
Based on Table 3, the skin friction coefficient and Nusselt number is increase as $G r_{x}$ increases for nanofluid and hybrid nanofluid.

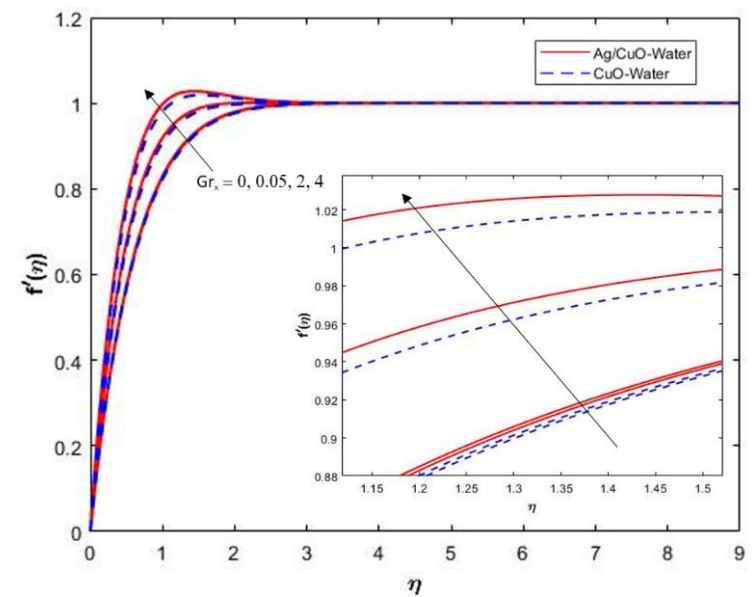

(a)

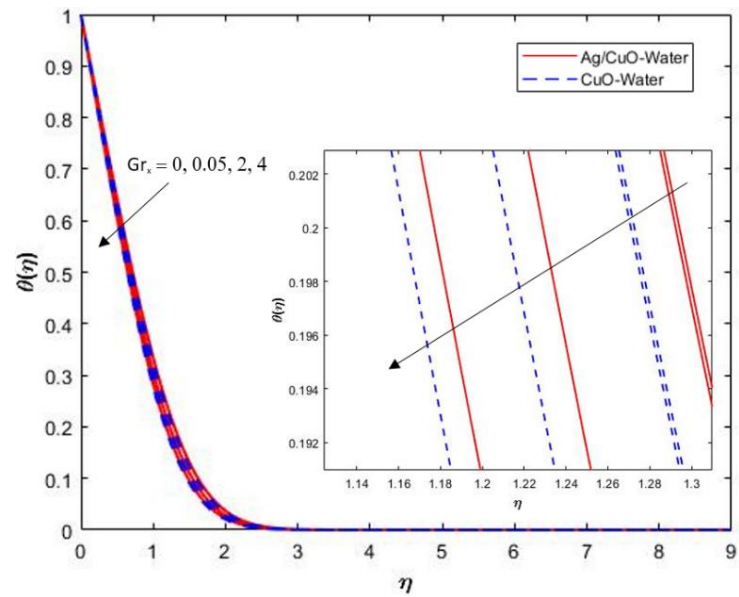

(b)

Fig. 5. Effects of $G r_{x}$ on (a) velocity profiles and (b) temperature profiles

Figure 6(a) displays the effect of $K_{p}$ on velocity profiles for $\mathrm{Ag} / \mathrm{CuO}-$ Water and CuO-Water. The figure displays the velocity profiles decrease when the $K_{p}$ increase. The permeability of a medium is known to be related to the porosity. The permeability shows a porous material's ability to let the fluids pass through it. As a result of enhancing porosity, permeability is enhanced which leads to increased fluid flow in supposed porous medium. The velocity profiles of $\mathrm{Ag} / \mathrm{CuO}-\mathrm{Water}$ is higher than CuO-Water. The momentum boundary layer thickness increase for both nanofluid and hybrid nanofluid. Figure 6(b) displays the effect of $K_{p}$ on temperature profiles for $\mathrm{Ag} / \mathrm{CuO}-\mathrm{Water}$ and CuOWater. The temperature profiles and thermal boundary layer thickness increase for both $\mathrm{Ag} / \mathrm{CuO}$ Water and CuO-Water when the value of $K_{p}$ increase. The main reason for temperature reduction is thermal conductivity and specific heat that is decaying because of the influence of porosity. The temperature profiles of $\mathrm{Ag} / \mathrm{CuO}-$ Water is higher than CuO-Water. When $K_{p} \rightarrow \infty$, there is no force in the velocity of the fluid. The magnitude of skin friction coefficient and Nusselt number is decrease as $K_{p}$ increases for nanofluid and hybrid nanofluid in Table 3.

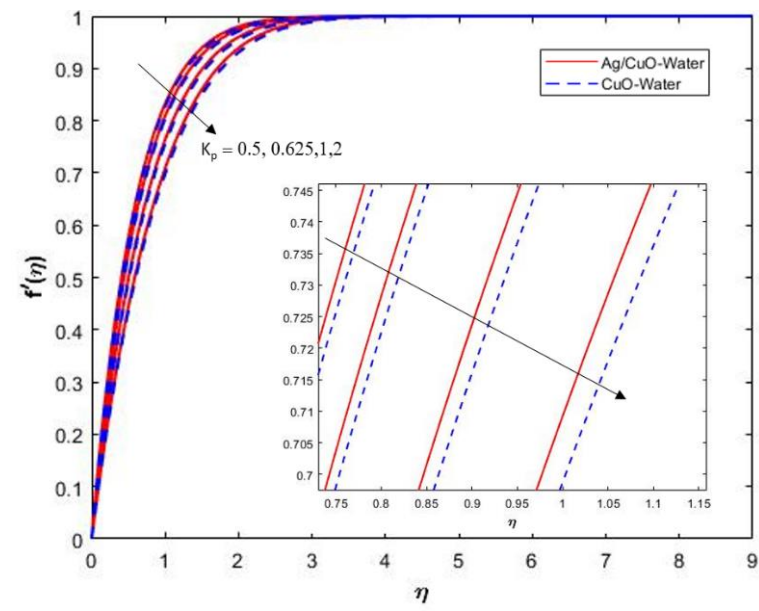

(a)

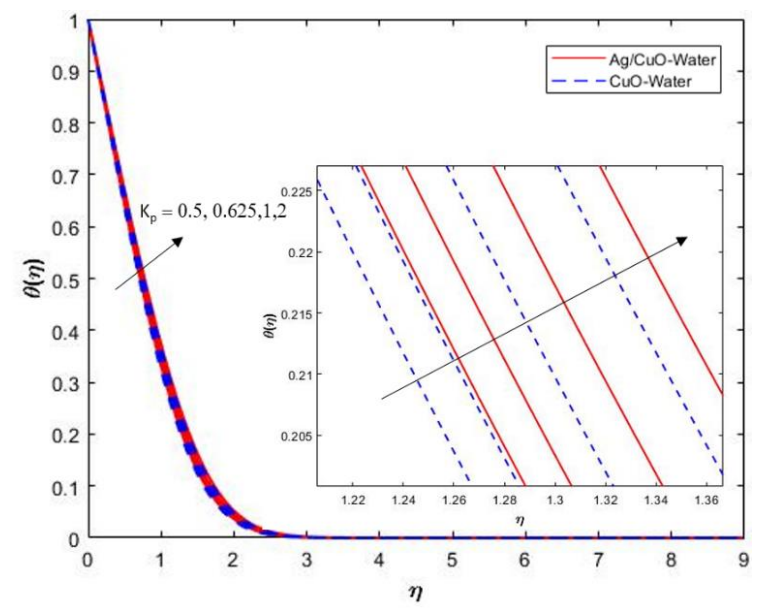

(b)

Fig. 6. Effects of $K_{p}$ on (a) velocity profiles and (b) temperature profiles 


\section{Table 3}

Effects of Skin Friction and Nusselt number for water, CuO-Water and Ag/CuO-Water

\begin{tabular}{clllllll}
\hline$\alpha$ & $M$ & $G r_{x}$ & $K_{p}$ & $\begin{array}{l}\text { Ag/Cuo-Water } \\
\phi_{1}=0.1, \phi_{2}=0.1\end{array}$ & & $\begin{array}{l}\text { Cuo-Water } \\
\phi_{1}=0.2, \phi_{2}=0\end{array}$ \\
\cline { 3 - 7 } & & & & Skin Friction & Nusselt Number & Skin Friction & Nusselt Number \\
\hline $0^{\circ}$ & 1 & 0.1 & 0.5 & 0.745760 & 0.951181 & 0.715909 & 0.925406 \\
$45^{\circ}$ & & & & 2.062848 & 2.062848 & 2.104501 & 1.187267 \\
$70^{\circ}$ & & & & 2.666078 & 1.262453 & 2.728494 & 1.256155 \\
$90^{\circ}$ & & & & 2.824732 & 1.277539 & 2.892304 & 1.271588 \\
\hline $90^{\circ}$ & 0 & 0.1 & 0.5 & 2.506296 & 1.246289 & 2.571725 & 1.240458 \\
& 1 & & & 2.824732 & 1.277539 & 2.892304 & 1.271588 \\
& 2 & & & 3.110683 & 1.302588 & 3.180648 & 1.296627 \\
& 3 & & & 3.372420 & 1.323408 & 3.444870 & 1.317492 \\
\hline $90^{\circ}$ & 1 & 0 & 0.5 & 2.788080 & 1.273518 & 2.857244 & 1.267843 \\
& 0.05 & & 2.806419 & 1.275533 & 2.874785 & 1.269719 \\
& 2 & & 3.503459 & 1.348200 & 3.542492 & 1.337709 \\
& 4 & & 4.187494 & 1.413192 & 4.199185 & 1.398987 \\
\hline $90^{\circ}$ & 1 & 0.1 & 0.5 & 2.824732 & 1.277539 & 2.892304 & 1.271588 \\
& & 0.625 & 2.613271 & 1.257224 & 2.672354 & 1.250643 \\
& & 1 & 2.259230 & 1.219127 & 2.303273 & 1.211186 \\
& & 2 & 1.914909 & 1.176022 & 1.942822 & 1.166169 \\
\hline
\end{tabular}

Table 4 shows the comparison of skin friction and Nusselt number for water, CuO-Water and $\mathrm{Ag} / \mathrm{CuO}-$ Water. Based on that, it shown the value of skin friction of nanofluid (CuO-Water) is higher than hybrid nanofluid ( $\mathrm{Ag} / \mathrm{CuO}$-Water) and base fluid (Water). While the value of Nusselt number shows that hybrid nanofluid ( $\mathrm{Ag} / \mathrm{CuO}-\mathrm{Water}$ ) is higher than nanofluid (CuO-Water) followed by base fluid (Water). So, we can conclude that the hybrid nanofluid ( $\mathrm{Ag} / \mathrm{CuO}-$ Water) has higher rate of heat transfer than nanofluid (CuO-Water) and base fluid (Water). From Table 4, it can be concluded that the present of nanoparticles give significant impact on skin friction and Nusselt number. In percentage-wise:

- the skin friction factor is increased by $61.62 \%$ while for Nusselt number is increased by $36.11 \%$ (comparison between water and CuO-Water).

- the skin friction factor is increased by $57.84 \%$ while for Nusselt number is increased by $36.02 \%$ (comparison between water and $\mathrm{Ag} / \mathrm{CuO}-$ Water).

- the skin friction factor is decreased by $2.34 \%$ while for Nusselt number is increased by $0.48 \%$ (Comparison between $\mathrm{Ag} / \mathrm{CuO}-$ water and CuO-Water).

Table 4

Effects of Skin Friction and Nusselt number for water, CuO-Water and $\mathrm{Ag} / \mathrm{CuO}-$ Water

\begin{tabular}{lllllllll}
\hline$\alpha$ & $M$ & $\phi_{1}$ & $\phi_{2}$ & $G r_{x}$ & $K_{p}$ & Skin Friction & Nusselt Number & \\
\hline $90^{\circ}$ & 1 & 0 & 0 & 0.1 & 0.5 & 1.789623 & 0.938000 & Water \\
& & 0.2 & 0 & & & 2.892304 & 1.271588 & CuO-Water \\
& & 0.1 & 0.1 & & & 2.824732 & 1.277539 & $\mathrm{Ag} / \mathrm{CuO}-$ Water \\
\hline
\end{tabular}

\section{Conclusions}

This paper study on the effects an aligned magnetic field of hybrid nanofluid over a vertical plate through porous medium with constant wall boundary condition. The influences of the aligned angle of magnetic field, $\alpha$, interaction of magnetic field, $M$, volume fraction of nanoparticles, $\phi$, Local 
Grashof number parameter, $G r_{x}$, and porous parameters, $K_{p}$ on effect of base fluid, nanofluid and hybrid nanofluid results obtained:

i. $\mathrm{Ag} / \mathrm{CuO}-$ Water (hybrid nanofluid) has higher rate of heat transfer than water (base fluid) and CuO-Water (nanofluid).

ii. With an increase in value of $\alpha, M$, and $G r_{x}$ the velocity profile increases. The increase in the value of $\phi_{1}$ and $\phi_{2}$ and $K_{p}$ results in a decrease of the velocity profiles.

iii. The temperature profile decreases with an increase in value of $\alpha, M$, and $G r_{x}$. A rise in the value of $\phi_{1}$ and $\phi_{2}$ and $K_{p}$ raises the temperature profiles.

iv. The skin friction and Nusselt number increase due to the rise in $\alpha, M$, and $G r_{x}$ except for $K_{p}, \phi_{1}$ and $\phi_{2}$.

v. In general, hybrid nanofluid heat transfer rate is better than nanofluids with affected by $\alpha$, $M, K_{p}, G r_{x}, \phi_{1}$ and $\phi_{2}$ parameters.

\section{Acknowledgement}

The authors extend their appreciation to Universiti Teknologi MARA Cawangan Kedah for funding this work through Geran Dana Kecemerlangan under grant number 600-UiTMKDH (PJI.5/4/1) (9/2018).

\section{References}

[1] Kamila, Susmita, and VR Venu Gopal. "Acoustics and thermal studies of conventional heat transfer fluids mixed with ZnO nano flakes at different temperatures." Heliyon 5, no. 9 (2019): e02445. https://doi.org/10.1016/i.heliyon.2019.e02445

[2] Choi, S. US, and Jeffrey A. Eastman. Enhancing thermal conductivity of fluids with nanoparticles. No. ANL/MSD/CP84938; CONF-951135-29. Argonne National Lab., IL (United States), 1995.

[3] Eastman, Jeffery A., U. S. Choi, Shaoping Li, L. J. Thompson, and Shinpyo Lee. "Enhanced thermal conductivity through the development of nanofluids." MRS Online Proceedings Library (OPL) 457 (1996). https://doi.org/10.1557/PROC-457-3

[4] Ganga, B., S. Mohamed Yusuff Ansari, N. Vishnu Ganesh, and AK Abdul Hakeem. "Hydromagnetic flow and radiative heat transfer of nanofluid past a vertical plate." Journal of Taibah University for Science 11, no. 6 (2017): 12001213. https://doi.org/10.1016/i.jtusci.2015.12.005

[5] Hussanan, Abid, Mohd Zuki Salleh, Ilyas Khan, and Sharidan Shafie. "Convection heat transfer in micropolar nanofluids with oxide nanoparticles in water, kerosene and engine oil." Journal of Molecular Liquids 229 (2017): 482-488. https://doi.org/10.1016/i.molliq.2016.12.040

[6] Hussanan, Abid, Sidra Aman, Zulkhibri Ismail, Mohd Zuki Salleh, and Basuki Widodo. "Unsteady Natural Convection of Sodium Alginate Viscoplastic Casson Based Based Nanofluid Flow over a Vertical Plate with Leading Edge Accretion/Ablation." Journal of Advanced Research in Fluid Mechanics and Thermal Sciences 45, no. 1 (2018): $92-$ 98.

[7] Farahani, Somayeh Davoodabadi, Mahdi Alibeigi, and Hamed Hossienabadi Farahani. "The Uniform Magnetic Field Efficacy on Heat Transfer of Nanofluid Flow in A Flat Tube." Journal of Advanced Research in Numerical Heat Transfer 5, no. 1 (2021): 9-27.

[8] Mahat, Rahimah, Sharidan Shafie, and Fatihhi Januddi. "Numerical Analysis of Mixed Convection Flow Past a Symmetric Cylinder with Viscous Dissipation in Viscoelastic Nanofluid." CFD Letters 13, no. 2 (2021): 12-28. https://doi.org/10.37934/cfdl.13.2.1228

[9] Yıldız, Çağatay, Müslüm Arıcı, and Hasan Karabay. "Comparison of a theoretical and experimental thermal conductivity model on the heat transfer performance of Al2O3-SiO2/water hybrid-nanofluid." International Journal of Heat and Mass Transfer 140 (2019): 598-605. https://doi.org/10.1016/i.ijheatmasstransfer.2019.06.028

[10] Khashi'ie, Najiyah Safwa, Norihan Md Arifin, and Ioan Pop. "Non-Darcy mixed convection of hybrid nanofluid with thermal dispersion along a vertical plate embedded in a porous medium." International Communications in Heat and Mass Transfer 118 (2020): 104866. https://doi.org/10.1016/i.icheatmasstransfer.2020.104866 
[11] Waini, Iskandar, Anuar Ishak, Teodor Groşan, and loan Pop. "Mixed convection of a hybrid nanofluid flow along a vertical surface embedded in a porous medium." International Communications in Heat and Mass Transfer 114 (2020): 104565. https://doi.org/10.1016/j.icheatmasstransfer.2020.104565

[12] Sundar, L. Syam, K. V. Sharma, Manoj K. Singh, and A. C. M. Sousa. "Hybrid nanofluids preparation, thermal properties, heat transfer and friction factor-a review." Renewable and Sustainable Energy Reviews 68 (2017): 185198. https://doi.org/10.1016/j.rser.2016.09.108

[13] Huminic, Gabriela, and Angel Huminic. "Hybrid nanofluids for heat transfer applications-a state-of-the-art review." International Journal of Heat and Mass Transfer $125 \quad$ (2018): 82-103. https://doi.org/10.1016/j.ijheatmasstransfer.2018.04.059

[14] Sajid, Muhammad Usman, and Hafiz Muhammad Ali. "Thermal conductivity of hybrid nanofluids: a critical review." International Journal of Heat and Mass Transfer $126 \quad$ (2018): $211-234$. https://doi.org/10.1016/j.ijheatmasstransfer.2018.05.021

[15] Waini, Iskandar, Anuar Ishak, and loan Pop. "Transpiration effects on hybrid nanofluid flow and heat transfer over a stretching/shrinking sheet with uniform shear flow." Alexandria Engineering Journal 59, no. 1 (2020): 91-99. https://doi.org/10.1016/i.aej.2019.12.010

[16] Ali, I. R., Ammar I. Alsabery, N. A. Bakar, and Rozaini Roslan. "Mixed Convection in a Lid-Driven Horizontal Rectangular Cavity Filled with Hybrid Nanofluid by Finite Volume Method." Journal of Advanced Research in Micro and Nano Engineering 1, no. 1 (2020): 38-49.

[17] Khashi'ie, Najiyah Safwa, Norihan Md Arifin, and loan Pop. "Mixed convective stagnation point flow towards a vertical Riga plate in hybrid Cu-Al2O3/water nanofluid." Mathematics 8, no. 6 (2020): 912. https://doi.org/10.3390/math8060912

[18] Reddy, P. Sudarsana, Ali J. Chamkha, and Ali Al-Mudhaf. "MHD heat and mass transfer flow of a nanofluid over an inclined vertical porous plate with radiation and heat generation/absorption." Advanced Powder Technology 28, no. 3 (2017): 1008-1017. https://doi.org/10.1016/j.apt.2017.01.005

[19] Ilias, Mohd Rijal, Nur Sa'aidah Ismail, Nurul Hidayah Ab Raji, Noraihan Afiqah Rawi, and Sharidan Shafie. "Unsteady aligned MHD boundary layer flow and heat transfer of a magnetic nanofluids past an inclined plate." International Journal of Mechanical Engineering and Robotics Research 9, no. 2 (2020). https://doi.org/10.18178/ijmerr.9.2.197$\underline{206}$

[20] Ilias, Mohd Rijal, Noraihan Afiqah Rawi, and Sharidan Shafie. "MHD Free Convection Flow and Heat Transfer of Ferrofluids over a Vertical Flat Plate with Aligned and Transverse Magnetic Field." Indian Journal of Science and Technology 9, no. 36 (2016). https://doi.org/10.17485/ijst/2016/v9i36/97347

[21] Ilias, Mohd Rijal, Ismail N. S'aidah, W. S. Esah, and C. Hussain. "Unsteady aligned MHD boundary layer flow of a magnetic nanofluid over a wedge." International Journal of Civil Engineering and Technology (IJCIET) 9 (2018): 794810.

[22] Ilias, Mohd Rijal, Noraihan Afiqah Rawi, and Sharidan Shafie. "Steady aligned MHD free convection of Ferrofluids flow over an inclined plate." Journal of Mechanical Engineering (JMechE) 14, no. 2 (2017): 1-15.

[23] Reddy, P. Sudarsana, P. Sreedevi, and Ali J. Chamkha. "MHD boundary layer flow, heat and mass transfer analysis over a rotating disk through porous medium saturated by $\mathrm{Cu}$-water and Ag-water nanofluid with chemical reaction." Powder Technology 307 (2017): 46-55. https://doi.org/10.1016/j.powtec.2016.11.017

[24] Ilias, Mohd Rijal, Noraihan Afiqah Rawi, and Sharidan Shafie. "Natural convection of ferrofluid from a fixed vertical plate with aligned magnetic field and convective boundary condition." Malaysian Journal of Fundamental and Applied Sciences 13, no. 3 (2017): 224-229. https://doi.org/10.11113/mjfas.v13n3.651

[25] Ashgar, Adnan, and The Yuan Ying. "Three Dimensional MHD Hybrid Nanofluid Flow with Rotating Stretching/Shrinking Sheet and Joule Heating." CFD Letters 13, no. 8 (2021): 1-19. https://doi.org/10.37934/cfdl.13.8.119

[26] Umavathi, J. C., and K. Hemavathi. "Flow and heat transfer of composite porous medium saturated with nanofluid." Propulsion and Power Research 8, no. 2 (2019): 173-181. https://doi.org/10.1016/j.jppr.2019.01.010

[27] Goud, B. Shankar, B. Suresh Babu, MN Raja Shekar, and G. Srinivas. "Mass transfer effects on MHD flow through porous medium past an exponentially accelerated inclined plate with variable temperature and thermal radiation." International Journal of Thermofluid Science and Technology 6, no. 4 (2019). https://doi.org/10.36963/IJTST.19060402

[28] Das, Sanatan, Rabindra Nath Jana, and Oluwole Daniel Makinde. "MHD flow of Cu-Al2O3/water hybrid nanofluid in porous channel: analysis of entropy generation." In Defect and Diffusion Forum, vol. 377, pp. 42-61. Trans Tech Publications Ltd, 2017. https://doi.org/10.4028/www.scientific.net/DDF.377.42

[29] Mansour, M. A., Sadia Siddiqa, Rama Subba Reddy Gorla, and A. M. Rashad. "Effects of heat source and sink on entropy generation and MHD natural convection of Al2O3-Cu/water hybrid nanofluid filled with square porous cavity." Thermal Science and Engineering Progress 6 (2018): 57-71. https://doi.org/10.1016/j.tsep.2017.10.014 
[30] Lavanya, Bommanna. "MHD Rotating Flow Through a Porous Medium with Heat and Mass Transfer." Journal of Advanced Research in Fluid Mechanics and Thermal Sciences 54, no. 2 (2019): 221-231.

[31] Lavanya, Bommanna. "Hall Current and Thermal Radiation Effects on Heat and Mass Transfer of Unsteady MHD Flow of a Viscoelastic Micropolar Fluid through a Porous Medium." Journal of Advanced Research in Fluid Mechanics and Thermal Sciences 68, no. 1 (2020): 1-10. https://doi.org/10.37934/arfmts.68.1.110

[32] Mahmood, Mohammed Ali, Mustafa Abdulsalam Mustafa, Mohammad M. Al-Azzawi, and Atheer Raheem Abdullah. "Natural convection heat transfer in a concentric annulus vertical cylinders embedded with porous media." Journal of Advanced Research in Fluid Mechanics and Thermal Sciences 66, no. 2 (2020): 65-83.

[33] Nagasasikala, Madduleti, and Bommanna Lavanya. "Heat and mass transfer of a MHD flow of a nanofluid through a porous medium in an annular, circular region with outer cylinder maintained at constant heat flux." CFD Letters 11, no. 9 (2019): 32-58.

[34] Anwar, Talha, Poom Kumam, and Wiboonsak Watthayu. "An exact analysis of unsteady MHD free convection flow of some nanofluids with ramped wall velocity and ramped wall temperature accounting heat radiation and injection/consumption." Scientific Reports 10, no. 1 (2020): 1-19. https://doi.org/10.1038/s41598-020-74739-w

[35] Pasha, Amjad Ali, Meshal Nuwaym Al-Harbi, Surfarazhussain S. Halkarni, Nazrul Islam, D. Siva Krishna Reddy, S. Nadaraja Pillai, and Ufaith Qadiri. "CFD study of Convective Heat Transfer of Water Flow Through Micro-Pipe with Mixed Constant Wall Temperature and Heat Flux Wall Boundary Conditions." CFD Letters 13, no. 7 (2021): 13-26. https://doi.org/10.37934/cfdl.13.7.1326

[36] Hemadri, Vadiraj, G. S. Biradar, Nishant Shah, Richie Garg, U. V. Bhandarkar, and Amit Agrawal. "Experimental study of heat transfer in rarefied gas flow in a circular tube with constant wall temperature." Experimental Thermal and Fluid Science 93 (2018): 326-333. https://doi.org/10.1016/j.expthermflusci.2017.12.030

[37] Jafarimoghaddam, A., and S. Aberoumand. "On the implementation of Cu/Ethylene Glycol nanofluids inside an annular pipe under a constant wall temperature boundary condition." Heat Transfer-Asian Research 46, no. 7 (2017): 647-655. https://doi.org/10.1002/htj.21235

[38] Asako, Yutaka, Shye Yunn Heng, and Chungpyo Hong. "On temperature jump condition for turbulent slip flow in a quasi-fully developed region of micro-channel with constant wall temperature." International Journal of Thermal Sciences 136 (2019): 467-472. https://doi.org/10.1016/j.ijthermalsci.2018.10.040

[39] Hayat, Tanzila, and S. Nadeem. "Heat transfer enhancement with Ag-CuO/water hybrid nanofluid." Results in Physics 7 (2017): 2317-2324. https://doi.org/10.1016/j.rinp.2017.06.034

[40] Tippa, Sowmya, Marneni Narahari, and Rajashekhar Pendyala. "Unsteady natural convection flow of nanofluids past a semi-infinite isothermal vertical plate." In AIP Conference Proceedings, vol. 1787, no. 1, p. 020014. AIP Publishing LLC, 2016. https://doi.org/10.1063/1.4968063

[41] Ahmad, Syakila, Azizah Mohd Rohni, and Ioan Pop. "Blasius and Sakiadis problems in nanofluids." Acta Mechanica 218, no. 3 (2011): 195-204. https://doi.org/10.1007/s00707-010-0414-6

[42] Blasius, H. "Crenzschicluen in I'lussigkcitcn mit kleiner Reibung." Zeitschrift für angewandte Mathematik und Physik 56 (1908): 1-37. 